Please cite this article in press as: Stubbe D et al., Critical assessment of the Lactarius gerardii species complex (Russulales), Fungal Biology (2010), doi:10.1016/j.funbio.2010.01.008

\title{
Critical assessment of the Lactarius gerardii species complex
}

\section{(Russulales)}

Dirk Stubbe*, Jorinde Nuytinck, Annemieke Verbeken

Research Group Mycology, Department of Biology, Ghent University, K.L. Ledeganckstraat 35, 9000 Gent, Belgium

Dirk.Stubbe@UGent.be, Jorinde.Nuytinck@UGent.be, Mieke.Verbeken@UGent.be

* Corresponding author. Tel.: +32 926450 69, fax: +32 926453 34. E-mail address:

Dirk.Stubbe@UGent.be

\section{Running title}

The Lactarius gerardii species complex

\begin{abstract}
This paper investigates species delimitation within the Lactarius gerardii species complex and explores its taxonomic and geographical extent. A combined molecular phylogeny based on ITS, LSU and rpb2 gene sequences is constructed and morphological characters are evaluated. While L. gerardii was originally described from North America, it has later been reported from all-over Asia. Therefore a worldwide sampling range was aimed at, including species exhibiting morphological affinities with $L$. gerardii. The phylogenetic analyses indicate that intercontinental conspecificity in L. gerardii is absent. Thirty strongly supported
\end{abstract}


clades are retrieved of which 18 are morphologically identifiable species. The group is elevated to Lactarius subg. Gerardii stat. nov. It includes, apart from L. gerardii s.l., L. atrovelutinus, L. bicolor, L. ochrogalactus, L. petersenii, L. reticulatovenosus, L. sepiaceus, L. subgerardii and L. wirrabara, as well as the pleurotoid L. uyedae. The paraphyletic nature of the genus Lactarius is confirmed. Lactarius subg. Gerardii appears not affiliated with $L$. subg. Plinthogalus and this can be substantiated morphologically. No representatives are known from Europe, Africa or South America. The high frequency of intercontinental sister relationships observed between America, Asia and the Australian region, suggests multiple migration and speciation events have occurred across continents.

\section{keywords}

biogeography; phylogeography; cryptic species; ectomycorrhiza; Lactifluus. 


\section{Introduction}

Lactarius, also known as the genus of the milkcaps, exhibits the characteristic feature of exuding a latex-like substance when injured. The genus has a subcosmopolitan distribution and is one of the main ectomycorrhizal symbionts in many vegetations ranging from the dipterocarp rainforests in South-east Asia over the Mediterranean Cistus vegetations to the boreal, coniferous forests. Recent work of Buyck et al. (2008) demonstrated that the genera Russula and Lactarius are paraphyletic. This resulted in the creation of the new and morphologically distinct genus Multifurca, accommodating $M$. furcatus (formerly assigned to Lactarius) and most species of former R. subsect. Ochricompactae (Buyck et al. 2008). While the remainder of Russula appears monophyletic, the results of Buyck et al. (2008) also indicate that Lactarius should be further split up into two separate genera, with one genus containing L. subgenera Russularia, Piperites and Plinthogalus and the other containing $L$. subgenera Lactarius, Lactifluus and Lactariopsis and L. sect. Edules (Buyck et al. 2008). A formal proposal is currently submitted to conserve the name Lactarius for the first genus and to use the name Lactifluus for the latter (Buyck et al. 2010). Here we maintain the use of Lactarius to refer to all milkcaps, except $M$. furcatus.

Lactarius gerardii Peck 1873 was described from eastern North America where it is regarded as a rather common species. Because of the velutinous aspect and brown colour of the cap, the lack of macrocystidia in the hymenium and a reticulate spore ornamentation, it fits well in $L$. subg. Plinthogalus (Hesler \& Smith 1979). Its white and widely spaced lamellae contrasting with the dark brown cap and stipe and the absence of any discolorations of the context or latex have lead to the reputation of being an easily recognizable species. While L. gerardii is not known to occur in western North America, the species has been reported all-over Asia (Das \& Sharma 2005; Imazeki et al. 1988; Le et al. 2007; Lee et al. 2002; Wang et al. 2004; Wu \& 
Mueller 1997). Specimens identified as L. aff. gerardii have been collected from Costa Rica to Newfoundland and from Japan to the western slopes of the Himalaya in India. Earlier, we have included Thai and American specimens in preliminary analyses to test the intercontinental conspecificity of L. gerardii (Le et al. 2007). The results showed that American and Thai specimens should be considered as different species. This was in line with the findings of Nuytinck et al. (2007), where the absence of Asian/American conspecificity could be demonstrated for $L$. sect. Deliciosi. However, our results also indicated that the Thai 'L. gerardii' consisted of several species. For a better appreciation of this species complex, we expanded our sampling range to a global scale and also tested species with a morphological resemblance to L. gerardii for their putative kinship.

The L. gerardii complex is an interesting case study for several reasons. Lactarius gerardii s.l. is considered as a common and easily recognizable species with a wide-spread, intercontinental distribution - in certain areas it even has a commercial value as an edible mushroom (Wang et al. 2004). Some morphological variability has been noticed in Asian specimens, but this has not been assessed molecularly (Le et al. 2007; Wang 2008). Recent molecular studies of Thai and Malaysian species of L. subg. Plinthogalus suggested $L$. gerardii should be removed from L. subg. Plinthogalus (Le et al. 2007; Stubbe et al. 2008), while the recent rearrangements within the Russulaceae (Buyck et al. 2008, 2010), called for a re-evaluation of the $L$. gerardii complex at the genus level.

The main goals of this paper are: (1) to determine the extent of the species complex both taxonomically and biogeographically by constructing a worldwide phylogeny of L. gerardii s.l.; (2) to reconsider its taxonomical position in light of the new findings in the Russulaceae; (3) to confront phylogenetic species delimitation with morphological characters. 
The description of Lactarius gerardii was based on three collections made by W.R. Gerard, in Poughkeepsie, Albany and Croghan (New York) of which the first collection was later designated as lectotype (Smith \& Hesler 1962). Smith \& Hesler (1962) created L. series Gerardii, joining those species of $L$. subg. Plinthogalus with a truly white spore deposit: $L$. subrubescens, L. similissimus, L. fagicola, L. murrillianus and L. gerardii. The first two species differ from L. gerardii by turning reddish when injured, while L. fagicola turns brown when injured. Lactarius murrillianus is unchanging but has narrow and crowded lamellae as opposed to L. gerardii. Originally, Smith \& Hesler (1962) distinguished L. similissimus from L. subrubescens based on its narrower caulocystidia and more ellipsoid spores, but they later accepted these differences as variability within one species (Hesler \& Smith 1979). Hesler \& Smith (1979) synonymized $L$. similissimus with $L$. subrubescens and relegated it, as they did with $L$. fagicola, to a varietal level of $L$. gerardii, resulting in the currently accepted varieties L. gerardii var. subrubescens and L. gerardii var. fagicola. The taxon L. series Gerardii was no longer acknowledged in Hesler \& Smith (1979). Instead the authors introduced stirps Gerardii, based on the same criterion of a white spore deposit. Although the species were not listed, this implied the inclusion of $L$. gerardii, L. atro-olivaceus, L. louisii, L. petersenii, $L$. pseudogerardii and L. subgerardii (Hesler \& Smith 1979). Lactarius murrillianus was made a variety of $L$. subisabellinus, a species with a buff spore print, and was assigned to stirps Eburneus (Hesler \& Smith 1979).

\section{Materials and methods}

Sampling 
In order to achieve the best possible idea of the limits and extent of the species involved in the Lactarius gerardii complex, we aimed to use specimens from a wide geographical sampling range and to include all species of stirps Gerardii as well as those species whose morphology suggests a putative affinity with $L$. gerardii. The detailed list of our target species - all are members of $L$. subg. Plinthogalus - for this study was as follows : L. gerardii var. gerardii, $L$. gerardii var. subrubescens, L. gerardii var. fagicola, L. subgerardii, L. petersenii, L. atroolivaceus, L. pseudogerardii, L. louisii, L. xanthydrorheus, L. subtomentosus, L. subisabellinus var. murrillianus, L. chiapanensis, L. ochrogalactus, L. bicolor, L. reticulatovenosus, L. atrovelutinus, L. venosus, L. wirrabara and L. sepiaceus (Grgurinovic 1997; Hesler \& Smith 1979; McNabb 1971; Montoya et al. 1996; Stubbe et al. 2008; Verbeken \& Horak 1999b; Verbeken \& Horak 2002; Wang et al. 2006; Wang 2007). Phylogenetic research of the genus Lactarius as a whole, suggested an affinity of the pleurotoid L. uyedae with L. gerardii (J.N., unpubl.). Therefore, L. uyedae and other possibly related, pleurotoid species, L. panuoides, L. multiceps and L. brunellus (Henkel et al. 2000; Miller et al. 2002) were also considered as target group species. Multifurca furcata, M. ochricompacta and 14 non-target group Lactarius species were added to ascertain the position of L. gerardii in one of the three major clades containing milkcaps (Buyck et al. 2008): L. angiocarpus, L. baliophaeus, L. cyanescens, L. lignyotus, L. montoyae, L. picinus, L. romagnesii (L. subg. Plinthogalus); L. volemus, L. clarkeae (L. subg. Lactifluus); L. leucophaeus, L. glaucescens, L. piperatus (L. subg. Lactarius); L. camphoratus (L. subg. Russularia); L. pubescens (L. subg. Piperites) (Das \& Sharma 2004; Eberhardt \& Verbeken 2004; Heilmann-Clausen et al. 1998.; Lalli \& Pacioni 1992; Stubbe et al. 2007; Verbeken 2001a; Verbeken \& Horak 1999a). Furthermore, three Russula species were included (R. 
nigricans, $R$. persicina and $R$. camarophylla) and Auriscalpium vulgare was used to root the trees.

DNA extraction, PCR, sequencing and nucleotide alignments

DNA was extracted from dried material using the PrepMan ${ }^{\circledR}$ Ultra Sample Reagent kit (Applied Biosystems Inc, Foster City, CA, U.S.A.). Extracts were purified with JetQuick General Clean-up columns (Genomed, Löhne, Germany). If DNA amplification proved unsuccessful, either the extraction protocol as described in Nuytinck et al. (2003) was used or a modified version, omitting the CTAB procedure and replacing it by an incubation with proteinase $\mathrm{K}$ for 18 hours at $45^{\circ} \mathrm{C}$. For several specimens older than 10 years, DNA was extracted with the Gentra Puregene Tissue kit (Qiagen Benelux B.V., Venlo, The Netherlands).

Protocols for PCR amplification and for sequencing follow Le et al. (2007). Three nuclear loci were amplified and sequenced: (1) the ITS region of the nuc rDNA, comprising ITS1, ITS2 and 5.8S, using primers ITS1-F and ITS4 (White et al. 1990), when necessary also using intermediate primers ITS2 and ITS3; (2) part of the LSU nuc rDNA, using primers LR0R and LR5 (R. Vilgalys lab 'http://www.biology.duke.edu/fungi/mycolab/primers.htm'); (3) the region between conserved domains 6 and 7 of the second largest subunit of the RNA polymerase II (rpb2), using primers bRPB2-6f and fRPB2-7cR (Liu et al. 1999; Matheny 2005). For specimens of which rpb2 amplification failed, intermediate primers have been constructed: i1f-RPB2 (5’-GCA RAA RAA GCA CGT DMG GTG GC-3’) (forward primer) and i2r-RPB2 (5’-ACV GTT TCC TCT TCT TCR GCR TC-3’) (reverse primer).

For all three loci, both forward and reverse sequences were obtained to resolve undetermined sites as much as possible. Sequences were assembled and edited with the Sequencher ${ }^{\mathrm{TM}} 4.8$ 
software (Gene Codes Corporation, Ann Arbor, MI, U.S.A.). Alignments were performed with the program MAFFT v6 (Katoh \& Toh 2008) with setting L-INS-i for ITS and setting FFT-NS-i for LSU and rpb2, and manually edited in BioEdit v7.0.9.0 (Hall 1999). The ITS alignment acquired from MAFFT was first subjected to the online program Gblocks v0.91b (Castresana 2000; Castresana lab 'http://molevol.cmima.csic.es/castresana/Gblocks.html') (settings: 'allow smaller final blocks', 'allow gaps within blocks') to delimit most of the ambiguously aligned segments. The combined alignment was then visually screened for additional, ambiguously aligned regions that needed to be excluded from further analyses. The only intron of the rpb2 marker was excluded entirely. The alignments are made available on the Russulales News website (Russulales News 'http://www.mtsn.tn.it/russulales-news') or can be obtained from the first author.

Phylogenetic analyses

The dataset was subdivided into 7 partitions: ITS1, 5.8S, ITS2, LSU, rpb2 first codon positions (rpb2-1), rpb2 second codon positions (rpb2-2) and rpb2 third codon positions (rpb2-3). To test compatibility of the combined nuc rDNA markers with the rpb2 marker, a ML Rapid Bootstrapping algorithm was implemented on both datasets for 500 replicates in the program RAxML v7.0.3, using the GTRMIX model with parameters optimized for each partition (Stamatakis 2006b; Stamatakis et al. 2008). The program Compat.py (Kauff \& Lutzoni 2002; Compat.py 'http: //www.lutzonilab.net/pages/download.shtml') was then used to detect conflicting clades with at least $70 \%$ BS support. The ML analysis of the combined dataset was executed with RAxML applying the Rapid Boostrapping algorithm as described above, followed by a ML tree search. Five partitioning strategies were tested: (1) ITS1, 5.8S, ITS2, LSU, rpb2-1, rpb2-2, rpb2-3; (2) ITS1+ITS2, 5.8S+LSU, rpb2-1, rpb2-2, rpb2-3; (3) 
ITS1+ITS2, 5.8S, LSU, rpb2-1+2, rpb2-3; (4) ITS1, 5.8S, ITS2, LSU, rpb2-1, rpb2-2+3; (5) ITS1+ITS2, 5.8S+LSU, rpb2-1, rpb2-2+3. Bayesian Inference analysis (BI) was executed in MrBayes v3.1.2 (Ronquist \& Huelsenbeck 2003) applying the GTR $+\mathrm{I}+\mathrm{G}$ model of character evolution. The BI was executed twice: once with maximized partitioning (strategy (1)) and once with 5 partitions (strategy (3)). For both analyses, two independent runs with four chains each were run for $10 \mathrm{M}$ generations, sampling every $100^{\text {th }}$ tree. The BI output was evaluated with Tracer (Tracer v1.4 'http://beast.bio.ed.ac.uk/Tracer'), convergence and stationarity of the two runs were checked and a burn-in value determined. A majority rule consensus tree was built after discarding the trees from the burn-in.

Morphological analyses

Macromorphological data of specimens are based on notes of the collectors. Specimens collected by the authors were described in daylight conditions. Colour changes of context and latex were observed up to 90 minutes after injury of the fruit body.

Microscopic features were studied on dried material. Terminology is adopted from Vellinga (1988) and, especially for pellis structures, from Verbeken (1998a). Pellis structures and hymenial elements were observed either in Congo-red in L4 or in Congo-red in ammonia and in a $10 \%$ aqueous potassium hydroxide solution. If necessary, slides were shortly heated above a flame to improve colour impregnation and rehydration. Spores were illustrated and described as observed in Melzer's reagent. Drawings of the spores were made with a drawing tube at $6000 \times$ magnification, pellis structures were drawn at $1600 \times$ magnification.

Identification of specimens was checked again after preliminary results of the molecular analyses and specimen names were corrected if necessary (Table 1). Type material was studied from the following species: L. gerardii var. gerardii (lectotype NYS 1341, NYS), L. 
gerardii var. subrubescens (Hesler 22326, TENN), L. gerardii var. fagicola (Smith 63693, MICH), L. subgerardii (Hesler 30321, TENN), L. ochrogalactus (E. Nagasawa 80-102, TMI), L. wirrabara (AD 9974, AD), L. sepiaceus (PDD 26384, PDD), L. bicolor (E.M. Burkill 73, K), L. uyedae (T. Uyeda, F), L. reticulativenosus (isotype Horak ZT 6472, GENT), L. venosus (isotype, Horak ZT 73-181, GENT).

\section{Results}

Sampling

Sequences of all target species could be included in the molecular analyses, except for $L$. brunellus, L. louisii, L. multiceps, L. pseudogerardii, L. subisabellinus var. murrillianus, L. subtomentosus, L. venosus and L. xanthydrorheus. Either no specimen was obtained or no useful DNA could be extracted, presumably due to the age of the specimens. The analyses include 92 specimens of target species, collected from Guyana, Costa Rica, the U.S.A., Canada, Japan, South Korea, China, Thailand, Nepal, India, Sri Lanka, Malaysia, Indonesia, Australia and New Zealand (Table 1). No specimens are known from Europe or Africa (including Madagascar) that show a putative affinity with L. gerardii or any of the other target species.

Molecular analyses

We produced 90 new sequences for the ITS region varying between 578 and 708 base pairs, 95 new LSU sequences varying between 804 and 906 base pairs, and 100 new rpb2 sequences 
varying between 326 and 827 base pairs (Table 1). The complete dataset (including non-target and outgroup species) involves 114 specimens, and contains 108 ITS, 110 LSU and 111 rpb2 sequences. Missing or highly incomplete sequences and sequences obtained from GenBank are indicated in Table 1. After exclusion of the ambiguously aligned regions, the concatenated alignment that is used for further analyses consists of 1925 characters (1-381: ITS, 382-1226: LSU, 1227-1925: rpb2).

Compat.py detected only two minor instances of conflicting clades between nuc rDNA and rpb2 BS analysis. The first one involves the internal relations of 3 Malaysian specimens (R.W.26708, S.S.L.1098, N.S.Y.1357), the second one indicates Lactarius camphoratus and L. pubescens form a monophyletic group in the rpb2 analysis but not in the nuc rDNA analysis. The five partitioning strategies tested for the ML analysis of the concatenated dataset, produced highly similar trees but strategies (1)-(3) gave a tree with a better likelihood value and clades with higher BS values then (4) and (5). Evaluation of the BI analysis output with Tracer showed that after 10M generations, the effective sample size of all parameters had amounted to at least 100 when strategy (3) was used. This was not the case with maximized partitioning and also, the PP values were slightly worse. Burn-in was set at $10 \%$. We will continue with the results and discussion based on ML and BI analyses using partitioning strategy (3) (ITS1+ITS2, 5.8S, LSU, rpb2-1+2, rpb2-3).

The ML and BI analyses result in nearly identical phylograms. The four major Russulaceae clades, as found by Buyck et al. (2008), are retrieved and the paraphyly of Lactarius is confirmed (Fig 1 A). The Russula clade, Multifurca clade and 'Lactarius 1' clade comprising L. camphoratus, L. pubescens and the species of $L$. subg. Plinthogalus, all have strong support in both ML and BI analyses. The remaining Lactarius species cluster together in a clade designated as 'Lactarius 2'. Lactarius subg. Plinthogalus is a strongly supported clade within 'Lactarius 1'. All target group species, except L. chiapanensis and L. panuoides, cluster 
together in one strongly supported clade, that we refer to as the 'Gerardii clade', which belongs in 'Lactarius 2'. Our results confirm the exclusion of L. gerardii from L. subg. Plinthogalus.

Phylogeny of the 'Gerardii clade’

Within the 'Gerardii clade' we find 30 terminal branches and strongly supported, monophyletic clades that correspond to 30 different species. Eighteen species are morphologically distinct (clades 2, 10-12, 14-15, 17, 20-30). The other species lack any distinctive, morphological features and in many cases exhibit considerable morphological and genetic variability. The North American, Asian and Australian species do not form monophyletic clades according to continent.

Clade 1 is a North American clade containing a.o. two specimens with a colour change in the context: a specimen identified as Lactarius atro-olivaceus (D.E. Desjardin 3630) which stains brownish lavender, and a specimen identified as L. gerardii var. subrubescens (R.E. Halling 6918). For some specimens of $A$. Verbeken brown spots were observed, attributed to insect damage. Spore ornamentation is variable but other micromorphologic features are consistent with the studied lectotype of L. gerardii var. gerardii. Specimen A.E. Franco-Molano 27-061989, the only specimen collected from New York, the same state as the lectotype, is on a separate branch in this clade.

Clade 2 represents a Thai species with unchanging context, rather wide-meshed spore ornamentation (Fig 2 A), short terminal elements in the pileipellis and similar marginal cells (on the lamella edge) with brown pigmentation. 
In clades 3-6, spore morphology is not uniform and genetic variability is high. For the specimens of North American clade 4, the same observations can be made as for clade 1, from which they cannot be distinguished morphologically.

Clades 7-8 are two very similar species with densely reticulate spore ornamentation. Malaysian species 7 has slightly higher and acute ornamentations. No detailed macroscopical descriptions were provided for these specimens.

In clade 9, morphology is variable and specimens cannot be distinguished from those of clade 6.

Clades 10, 11 and 14 (L. bicolor) are similar species with strikingly coloured lamella edges and low-ridged spores. Species 10 differs from L. bicolor (Fig 1 D) by its long and slender marginal cells and terminal elements. The Chinese species 11 is set apart by its larger spores. Clades 12 and 15 are two Sri Lankan species. Species 12 has characteristic spores bearing a reticulum of interconnected, acute spines (Fig 2 F). Species 15 (Fig 1 E, Fig 2 H) has dense and brown staining lamellae, and spores with firm ridges.

Clade 16 consists of specimen K. Das 4062. It had been identified, together with K. Das 4073 (clade 6) as L. gerardii var. subrubescens (Das \& Sharma 2004). The two species have similar morphologies.

Clade 17 corresponds with $L$. atrovelutinus, a species characterized by the short, terminal elements in the pileipellis, the small spores and a pinkening colour reaction (Fig $1 \mathrm{C}$ ).

Clades 13 and 18 correspond with L. cfr. wirrabara, originally described from Australia by Grgurinovic (1997), and $L$ cfr. sepiaceus, originally described from New Zealand by McNabb (1971), respectively. The micromorphologic features of these two species are very similar and do not allow to distinguish between them. All specimens are morphologically consistent with the type of L. wirrabara and a paratype of L. sepiaceus (PDD 31236, PDD) respectively, but the holotype of $L$. sepiaceus has mostly spores with a lower and denser reticulum. 
Macroscopically, L. sepiaceus should be the darkest of the two species, being more blackish brown, and its context should turn rapidly pink in contact with ferrous sulphate. Grgurinovic tested this for L. wirrabara but only on dried material, which gave no reaction. She provided no comparison of the two species. We designated clade 18 as $L$. cfr. sepiaceus since all specimens, except one, had been identified as L. sepiaceus and because the detailed description of the New Zealand specimen (P. Leonard 40509), mentioning the rapid pink reaction with ferrous sulphate, matches exactly the description of the species.

Clade 19 is a Malaysian species, similar to the Thai species 2, but the spores are slightly more densely reticulate and have many, minute, isolated warts between the ridges.

Clade 20 is labeled $L$. cfr. gerardii var. fagicola. The, often large, spores are similar to those of the type specimen, but the ridges are more acute (Fig $2 \mathrm{~J}$ ). A brownish colour change of the context was observed in D.E. Desjardin 3564 but absent in J. Nuytinck 07-029.

Clade 21 represents $L$. subgerardii. This species is recognized by its small stature and the spores ornamented by a mixture of ridges and interconnected, acute warts (Fig $2 \mathrm{~K}$ ).

Clade 22 consists of the type of $L$. reticulatovenosus, a small, Indonesian species with spores bearing irregular ridges (Fig $2 \mathrm{~L}$ ).

Clade 23 is a Malaysian specimen exhibiting a pinkening of the context. It differs from $L$. gerardii var. subrubescens and other species by a very rudimentary layer of globose cells in the pileipellis, small spores (av. $6.8 \times 5.7 \mu \mathrm{m}$ ) and the absence of distinct, marginal cells.

Clade 24 is a Costa Rican specimen collected in a high altitude (2600 m) Quercus forest. It is distinct from any North American collection because of its small basidiocarps with conspicuous, brown lamella edges and its particularly acute spore ornamentation.

Clades 25, 26 and 27 together form a monophyletic group of white, pleurotoid species, containing $L$. uyedae, described from Japan. The three species can be told apart by the shape 
of their macrocystidia. The Thai species (clade 25) also has smaller, and differently ornamented spores (Fig $2 \mathrm{M})$.

Clades 28, 29 and 30 are three species with spore ornamentation composed of interconnected warts and with latex that is brown (L. petersenii and L. ochrogalactus) or becomes brown ( $L$. aff. ochrogalactus). The North American L. petersenii is further characterized by its dense lamellae (Fig $1 \mathrm{~F}$ ) and low spore ornamentation (Fig $2 \mathrm{~N}$ ). In both the Japanese $L$. ochrogalactus and the Australian/New Zealand L. aff. ochrogalactus the context stains reddish pink and macrocystidia are present, but only L. ochrogalactus has thick-walled terminal elements. The macroscopic characteristics of $L$. aff. ochrogalactus correspond to Fuhrer's concept of L. wirrabara (Fuhrer 2005). However, his concept cannot be considered correct, since the pinkening of the context and the brown discoloration of the latex are not consistent with the original description of $L$. wirrabara and the spores of $L$. aff. ochrogalactus (Fig 2 O) are strikingly different from those of the type of L. wirrabara.

Diagnostic characters

Species of the 'Gerardii clade' can be morphologically recognized, based on five important characters: the white spore print, the reticulate spore ornamentation not higher than $2 \mu \mathrm{m}$ (Fig 2), the palisade structure in the pileipellis with globose cells in the subpellis (Fig 3), the lack of macrocystidia and the general habitus of a brown pileus and stipe contrasting with the white, mostly distant, lamellae (Fig 1 B-F). Some exceptions exist, like L. ochrogalactus, which has macrocystidia, and L. uyedae which is a white, pleurotoid species and also has macrocystidia in its hymenium.

Characters of diagnostic value within the 'Gerardii clade' are: 
Spore ornamentation - In most cases, accurate observation of the spore characteristics, and especially spore ornamentation, may allow identification of the different species. The reticulum can differ in density, its ridges can vary in thickness, height and regularity and warts can be differently shaped. Exceptions include L. cfr. sepiaceus and L. cfr. wirrabara (Fig 2 E, I), and L. bicolor and L. aff. bicolor (Fig 2 G) which cannot be distinguished based on spore characteristics.

Lamellar density - While most species of the 'Gerardii clade' have distantly spaced lamellae when mature, this is not the case for L. petersenii and the Sri Lankan species 15 (Fig 1 E-F). Lamella edge -The lamella edge may be concolorous with the pileus. This sometimes facilitates species recognition, especially when very conspicuous as in L. bicolor (Fig $1 \mathrm{D}$ ) and the species from clades 10, 11 and 24. In the Thai species of clade 9 and in L. sepiaceus this feature appears to be variable, being present in some basidiocarps and absent in others. However, in most clades, a coloured lamella edge is consistently absent. None of the North American species in the 'Gerardii clade' exhibit coloured lamella edges.

Colour and colour changes of latex and contex - These are important in identifying $L$. atrovelutinus, L. petersenii, L. ochrogalactus, L. aff. ochrogalactus and the species 15 . Colour changes of the context appear not consistent in clades 1, 4, 6 and 20, where only for some specimens a colour change has been noted by the collectors.

Pellis structures and marginal cells - All species have a clear palisade (Fig 3 A) in the pileipellis, except for $L$. cfr. sepiaceus and L. cfr. wirrabara which have a trichopalisade. Terminal elements of the pileipellis may differ in shape and length between species. When the lamella edge is concolorous with the pileus, the form of the terminal elements is often repeated in the marginal cells. Terminal elements and marginal cells allow to discriminate between L. bicolor and species 10 and between Thai species 2 and the other Thai species. 
Macrocystidia and thick-walled elements - Thick-walled pellis elements (cell walls min. 1 $\mu \mathrm{m}$ thick) and macrocystidia that are clearly distinct from developing basidia are rare in the 'Gerardii clade'. They are present in L. (aff.) ochrogalactus (clades 29-30) and in the three, pleurotoid species L. (aff.) uyedae (clades 25-27). The shape of the macrocystidia is speciesspecific in these pleurotoid species.

\section{Taxonomy}

Lactarius subg. Gerardii (A.H. Sm. \& Hesler) Stubbe stat. nov.

Basionym: Lactarius series Gerardii A.H. Sm. \& Hesler, Brittonia 14: 378, 1962

Type: Lactarius gerardii Peck, Bull. Buffalo Soc. Nat. Sci. 1: 57, 1873 (as L. 'geradii’)

Species: L. gerardii, L. subgerardii, L. petersenii, L. ochrogalactus, L. sepiaceus, L. wirrabara, L. reticulatovenosus, L. uyedae, L. bicolor, L. atrovelutinus.

Description: Brown and velutinous pileus and stipe with whitish, mostly distant lamellae. Sometimes small, white, pleurotoid species. White spore print. Spores reticulately ornamented with ridges or interconnected warts, not higher then $2 \mu \mathrm{m}$. Macrocystidia mostly lacking. Pileipellis usually a well-developed palisade.

\section{Discussion}

If the proposal to conserve the name Lactarius for what we referred to here as 'Lactarius 1', and to apply the name Lactifluus, for what we referred to here as 'Lactarius 2', gets accepted, then Lactarius subg. Gerardii will be transferred to Lactifluus.

Publication of the here newly discovered species is currently in preparation. 
The actual number of species belonging to L. subg. Gerardii is likely to be higher than we can demonstrate here. The phylogeny here presented suggests 30 species but not all putative members have been included in the analyses. The following species show morphological affinities, but still need to be tested molecularly: L. brunellus, L. louisii, L. multiceps, L. pseudogerardii, L. subisabellinus var. murillianus, L. subtomentosus, L. venosus and $L$. xanthydrorheus. Further sampling might reveal additional new species.

Ectomycorrhizal hosts that have been recorded for species of L. subg. Gerardii are Fagaceae (Fagus, Quercus, Lithocarpus, Castanopsis), Nothofagaceae (Nothofagus), Dipterocarpaceae (Shorea, Dipterocarpus), Myrtaceae (Eucalyptus) and conifers (Pinus, Tsuga, Abies). The subgenus inhabits forest biotopes, varying from deciduous, coniferous and mixed temperate forests to tropical montane forests and lowland rainforests. The currently known distribution covers Central America, eastern North America, eastern Asia, Southern China, the Himalayan region, Sri Lanka, South-east Asia, and the Australian region.

Lactarius subg. Plinthogalus and L. subg. Gerardii share the brown colours, the velutinous aspect, the reticulate spore ornamentation and the lack of macrocystidia. In L. subg. Plinthogalus spore print colours are never pure white, like in L. subg. Gerardii, but vary from cream to buff, and are among the darkest in the genus. The reticulate spore ornamentation in L. subg. Gerardii is often quite regular and ridges are not as venose and never winged or zebroid, as they can be in L. subg. Plinthogalus. Critical observation of the pileipellis is important to distinguish the two taxa (Fig 3). In L. subg. Gerardii the pileipellis is typically a palisade with a subpellis of multiple layers of globose cells (Fig 3 A). Especially the subpellis is different in L. subg. Plinthogalus, where, instead of distinct globose cells, it is composed of strongly inflated hyphal elements, that in most cases allow one to follow how individual elements are linked to one another. These hyphal elements are not so much globose, but rather pear-shaped and irregular in form (Fig $3 \mathrm{~B}$ ). 
One of the most notable problems that has come forth in this study of L. subg. Gerardii, is the position of the type species in the phylogeny. The type most likely belongs to either clade 1 or clade 4, but these clades cannot be distinguished from each other morphologically, nor could any useful DNA be extracted from the lectotype to ascertain its position molecularly. Besides that, North American specimens identified as L. gerardii var. subrubescens, L. gerardii var. fagicola and L. atro-olivaceus group together with specimens without a colour reaction, complicating interpretation of these colour reactions. A comprehensive study using detailed descriptions of newly collected North American specimens, might resolve these matters.

At least four species of $L$. subg. Gerardii exist in the Australian region: $L$. aff. uyedae, $L$. aff. ochrogalactus, L. sepiaceus and L. wirrabara. These last two species remain very difficult to tell apart but are not as closely related as their similar morphologies would suggest. The reaction of ferrous sulphate on fresh specimens of $L$. wirrabara should be tested. In the original descriptions, L. wirrabara was found near Eucalyptus and L. sepiaceus near Nothofagus. However, several of the Australian specimens of $L$. cfr. sepiaceus were also found with Eucalyptus. An ectomycorrhizal study could be useful to confirm the host tree. More New Zealand samples need to be checked to know whether L. cfr. wirrabara can also be found on the archipelago.

Lactarius chiapanensis, described from Mexico, was considered a member of L. subg. Plinthogalus, resembling L. petersenii and L. pseudogerardii (Montoya et al. 1996). It now is clear that the species belongs neither to L. subg. Plinthogalus, nor to L. subg. Gerardii. It appears closely related to the Australian L. clarkeae which has an orange and coarsely tomentose cap. Microscopically this makes sense, since their faintly ornamented spores and subcapitate macrocystidia are practically identical. Moreover, these are features that are atypical for L. subg. Gerardii or L. subg. Plinthogalus. 
The pleurotoid habitus of L. panuoides and L. uyedae, was developed independently from one another. In spite of this, we were unable to detect any morphological feature that can be related to their different phylogenetic position. The phylogenetic positions of L. brunellus and L. multiceps still need to be determined molecularly. It is curious to notice that a white spore print and thick-walled terminal elements appear present in all known, pleurotoid Lactarius species (Henkel et al. 2000; Miller et al. 2002; Redhead \& Norvell 1993; Verbeken 1998b).

\section{Biogeography}

One of the most striking observations that can be made from the phylogeny of $L$. subg. Gerardii is the multitude of intercontinental sister relationships between species from America, Asia and the Australian region. The species in this subgenus do not cluster together according to continent, and sympatric lineages are often distantly related. These results suggest that allopatric speciation, which is the most common speciation mechanism (Kohn 2005), is likely to be one of the major mechanisms responsible for the species diversity in $L$. subg. Gerardii. Migration was possible via land bridges in Beringia and in the Malesian region that have existed intermittently throughout the Tertiary and Quaternary. In the Tertiary, the Beringian land connections sustained broad-leaved, and later-on, coniferous forests (Graham 1993), which could have supported an ectomycorrhizal mycoflora. Even during the Pleistocene, Beringia experienced prolonged ice-free periods with shrub-tundra environments (Elias et al. 1997). In the Malesian region, a combination of land bridges and island hopping made migrations possible between Asia and Australia, starting from the mid-Miocene (Cox \& Moore 2006; Hewitt 2000). This would situate the first Australasian distributions earliest around 15 million years ago. Considering the limited genetic variability in L. cfr. sepiaceus and in L. aff. ochrogalactus, their Australian/New Zealand distribution appears to be recent 
and therefore most likely caused by long distance dispersal (LDD). LDD events between Australia and New Zealand have been demonstrated in Lentinula (Hibbett 2001) and in the ectomycorrhizal genus Pisolithus (Moyersoen et al. 2003). In fact, one cannot rule out LDD as an alternative explanation for the entire amphi-Pacific distribution. However if LDD would indeed be so prevalent, it would be difficult to explain the absence of $L$. subg. Gerardii species in Europe, western North America and, as far as we know, in South America and Africa. A possible explanation for the lack of European species could be the mass extinctions during the Quaternary glaciations, and the absence in western North America might be related to the uplift of the Rocky Mountains during the Tertiairy (Cox \& Moore 2006). The African continent was isolated during most of the Paleogene, until approximately 19 million years ago, when it collided with Europe (Cox \& Moore 2006), but a more recent barrier for colonization might have been the desertification of the Sahara and the Arabian Peninsula during the Pleistocene (Burgoyne et al. 2005; Cox \& Moore 2006). The possibility remains that related African species have simply not yet been discovered, given the relatively low exploration rate of particular biotopes on this continent. We have no knowledge of any South American collections with a putative affinity with $L$. gerardii. The one Costa Rican specimen included in the analyses, comes from high elevation Quercus forest and is no reference for the potential presence of $L$. subg. Gerardii in lowland tropical rainforests of South America. Still, a lower abundance of Russulaceae has been observed on this continent (Buyck and Ovrebo 2002; Verbeken 2001b).

Phylogeographic studies often try to find out whether or not the phylogeny is regionally structured (e.g. Old World versus New World clades, northern versus southern hemisphere) and whether or not species with a disjunct or intercontinental distribution truly exist. For $L$. subg. Gerardii we can say that it contains little geographical structure since many lineages have spread across two or three continents. The close relationship between eastern North 
American and Australasian species is evident but species with an intercontinental distribution have not been found. If we look at other phylogeographic studies involving ectomycorrhizal fungi, we find that close, intercontinental relationships are not uncommon, while disjunct populations of the same species are rather rare. Our results are comparable with those of Zhang et al. (2004) who demonstrated that Asian species of Amanita are often closely related to North American species, but they cannot not be confirmed as species with disjunct distributions. In the Amanita muscaria complex, there are several North American and Eurasian clades, but they do not cluster according to their geography (Geml et al. 2008). A study of matsutake and its close allies (Chapela \& Garbelotto 2004) revealed the existence of a circumboreal species and indicated that eastern North American and Asian species are closer related with one another than eastern with western North American species. Mueller et al (2001) focussed on the relationship between look-a-like species of Suillus from China and North America. They concluded that in most cases these species are not as closely related as the morphological similarities might suggest. However, their results also detected several species with an intercontinental distribution. The study of the Hysterangiales by Hosaka et al. (2008) is on a larger scale, and although it uncovered multiple intercontinental sister relations, the phylogeny is structured in southern hemisphere clades, a northern hemisphere clade and a mixed clade. Matheny et al. (2009) performed a large-scale study of the Inocybaceae which demonstrates that its phylogeography is mainly the result of ancient vicariance events and subsequent radiations. Despite some dispersal events, most Inocybaceae species cluster together with species from the same region ('North temperate', 'South temperate', 'paleotropics' or 'neotropics'). The phylogeography of L. subg. Gerardii is not inconsistent with the results of the above mentioned studies and if phylogeographical studies in the Russulales further progress, the subgenus will certainly be considered a 'mixed clade'. Still, 
the multitude of intercontinental sister relationships $L$. subg. Gerardii, in combination with its non-random distribution of on the globe remains intriguing.

\section{Acknowledgements}

The first author is supported by a scholarship of the Institute for the Promotion of Innovation through Science and Technology (IWT-Vlaanderen). We would like to express our sincere gratitude to all persons and herbaria who graciously provided specimens for this research: Kanad Das (BSD), Dennis Desjardin (SFSU), Lee Su See (FRIM), Roy Watling (E), David P. Lewis, Xiang-Hua Wang (HKAS), Eji Nagasawa (TMI), Roy Halling (NY), Christen Mortensen, Gregory Mueller (CHIC), Josephine Milne (MEL) and Leticia Montoya. We would especially like to thank Huyen Le Than, Genevieve Gates and Patrick Leonard for their contributions. We thank the reviewers for their suggestions to improve the manuscript.

\section{REFERENCES}

Burgoyne PM, van Wyk AE, Anderson JM, Schrire BD, 2005. Phanerozoic evolution of plants on the African plate. Journal of African Earth Sciences 43: 13-52.

Buyck B, Hofstetter V, Verbeken A, Walleyn R, 2010. Proposal to conserve Lactarius nom. cons. (Basidiomycota) with a conserved type. Taxon: in press.

Buyck B, Ovrebo CL, 2002. New and interesting Russula species from Panamá. Mycologia 94: 888-901. 
Buyck B, Hofstetter V, Eberhardt U, Verbeken A, Kauff F, 2008. Walking the thin line between Russula and Lactarius: the dilemma of Russula subsect. Ochricompactae. Fungal Diversity 28: 15-40.

Castresana J, 2000. Selection of conserved blocks from multiple alignments for their use in phylogenetic analysis. Molecular Biology and Evolution 17: 540-552.

Chapela IH, Garbelotto M, 2004. Phylogeography and evolution in matsutake and close allies inferred by analyses of its sequences and AFLPs. Mycologia 96: 730-741.

Cox CB, Moore PD, 2006. Biogeography. An Ecological and Evolutionary Approach, 7th edn. Blackwell Publishing, Malden, Oxford, Victoria.

Das K, Sharma JR, 2004. Lactarius in Kumaon Himalaya 2: New and interesting species of subgenus Plinthogali. Mycotaxon 89: 289-296.

Das K, Sharma JR, 2005. Russulaceae of Kumaon Himalaya. Govt. of India, Botanical Survey of India, Ministry of Environment \& Forests, Kolkata

Eberhardt U, Verbeken A, 2004. Sequestrate Lactarius species from tropical Africa: L. angiocarpus sp. nov. and L. dolichocaulis comb. nov. Mycological Research 108: 1042-1052. Elias SA, Short SK, Birks HH, 1997. Late Wisconsin environmenst of the Bering Land Bridge. Palaeogeography, Palaeoclimatology, Palaeoecology 136: 293-308.

Fuhrer B, 2005. A field guide to Australian fungi.Blooming Books Pty Ltd, Melbourne.

Graham A, 1993. History of the vegetation: Cretaceous (Maastrichtian)-Tertiary. In: Flora of North America Editorial Committee (eds), Flora of North America. Vol. 1. New York, Oxford, pp. 57-70.

Geml J, Tulloss RE, Laursen GA, Sazanova NA, Taylor DL, 2008. Evidence for strong interand intracontinental phylogeographic structure in amanita muscaria, a wind-dispersed ectomycorrhizal basidiomycete. Molecular Phylogenetics and Evolution 48: 694-701. 
Grgurinovic CA, 1997. Larger Fungi of South Australia. The Botanic Gardens of Adelaide and State Herbarium and The Flora and Fauna of South Australia Handbooks Committee, Adelaide.

Hall TA, 1999. BioEdit: a user-friendly biological sequence alignment editor and analysis program for Windows 95/98/NT. Nucleic Acids Symposium Series 41: 95-98.

Heilmann-Clausen J, Verbeken A, Vesterholt J, 1998. The genus Lactarius. Fungi of Northern Europe, vol. 2. Svampetryk, Mundelstrup.

Henkel TW, Aime MC, Miller SL, 2000. Systematics of pleurotoid Russulaceae from Guyana and Japan, with notes on their ectomycorrhizal status. Mycologia 92: 1119-1132.

Hesler LR, Smith AH, 1979. North American species of Lactarius. Univ. Michigan Press, Ann Arbor.

Hewitt G, 2000. The genetic legacy of the Quaternary ice ages. Nature 405: 907-913.

Hibbett DS, 2001. Shiitake mushrooms and molecular clocks: historical biogeography of Lentinula. Journal of Biogeography 28: 231-241.

Hosaka K, Castellano MA, Spatafora JW, 2008. Biogeography of Hysterangiales (Phallomycetidae, Basidiomycota). Mycological Research 112: 448-462.

Imazeki R, Otari Y, Hongo T, 1988. Nihon-no-Kinoko. Fungi of Japan. Yama-kei Publishers Co., Ltd., Tokyo .

Katoh K, Toh H, 2008. Recent developments in the MAFFT multiple sequence alignment program. Briefings in bioinformatics 9: 286-298.

Kauff F, Lutzoni M, 2002. Phylogeny of the Gyalectales and Ostropales (Ascomycota, Fungi): among and within order relationships based on nuclear ribosomal RNA small and large subunits. Molecular Phylogenetics and Evolution 25: 138-156.

Kohn LM, 2005. Mechanisms of fungal speciation. Annual Review of Phytopathology 43: 12.1-12.30. 
Lalli G, Pacioni G, 1992. Lactarius sect. Lactifluus and allied species. Mycotaxon 44: 155195.

Le HT, Stubbe D, Verbeken A, Nuytinck J, Lumyong S, Desjardin DE, 2007. Lactarius in Northern Thailand: 2. Lactarius subgenus Plinthogali. Fungal Diversity 27: 61-94.

Lee SS, Watling R, Sikin YN, 2002. Ectomycorrhizal basidiomata fruiting in lowland rain forests of Peninsular Malaysia. Bois et Forêts des Tropiques 274: 33-43.

Liu YJ, Wehlen S, Hall BD, 1999. Phylogenetic relationships among ascomycetes: evidence from an RNA polymerase II subunit. Molecular Biology and Evolution 16:1799-1808.

Matheny PB, 2005. Improving phylogenetic inference of mushrooms with RPB1 and RPB2 nucleotide sequences (Inocybe; Agaricales). Molecular Phylogenetics and Evolution 35:1-20. Matheny PB, Aime MC, Bougher NL, Buyck B, Desjardin DE, Horak E, Kropp BR, Lodge DJ, Soytong K, Trappe JM, Hibbett DS, 2009. Out of the Palaeotropics. Historical biogeography and diversification of the cosmopolitan ectomycorrhizal mushroom family Inocybaceae. Journal of Biogeography 36: 577-592.

McNabb RFR, 1971. The Russulaceae of New Zealand. 1. Lactarius DC ex S.F. Gray. New Zealand Journal of Botany 9: 46-66.

Miller SL, Aime MC, Henkel TW, 2002. Russulaceae of the Pakaraima Mountains of Guyana. I. New species of pleurotoid Lactarius. Mycologia 94: 545-553.

Montoya L, Band-Muñoz VM, Guzmán G, 1996. New and interesting species of Lactarius from Mexico including scanning electron microscope observations. Mycotaxon 57: 412-424. Mueller GM, Wu QW, Huang YQ, Guo SY, Aldana-Gomez R, Vilgalys R, 2001. Assessing biogeographic relationships between North American and Chinese macrofungi. Journal of Biogeography 28: 271-281. 
Nuytinck J, Verbeken A, Miller S, 2007. Worldwide phylogeny of Lactarius section Deliciosi inferred from ITS and glyceraldehyde-3-phosphate dehydrogenase gene sequences. Mycologia 99: 820-832.

Nuytinck J, Verbeken A, Delarue S, Walleyn R, 2003. Systematics of European sequestrate lactarioid Russulaceae with spiny spore ornamentation. Belgian Journal of Botany 136:145153.

Redhead SA, Norvell LL, 1993. Notes on Bondarzewia, Heterobasidion and Pleurogala. Mycotaxon 48: 371-380.

Ronquist F, Huelsenbeck JP, 2003. MrBayes 3: Bayesian phylogenetic inference under mixed models. Bioinformatics 19: 1572-1574.

Smith AH, Hesler LR, 1962. Studies on Lactarius - III. The North American species of section Plinthogali. Brittonia 14: 369-440.

Stamatakis A, 2006a. Phylogenetic models of rate heterogeneity: a high performance computing perspective. In: Proceedings of IPDPS 2006. Rhodos, p. 8.

Stamatakis A, 2006b. RAxML-VI-HPC: maximum likelihood-based phylogenetic analyses with thousands of taxa and mixed models. Bioinformatics 22: 2688-2690.

Stamatakis A, Hoover P, Rougemont J, 2008. A rapid bootstrap algorithm for the RAxML Web Servers. Systematic Biology 57: 758-771.

Stubbe D, Verbeken A, Watling R, 2007. Blue-staining species of Lactarius subgenus Plinthogali in Malaysia. Belgian Journal of Botany 140: 197-212.

Stubbe D, Nuytinck J, Verbeken A, 2008. Lactarius subgenus Plinthogalus of Malaysia. Fungal Diversity 32: 125-156.

Vellinga EC, 1988. Glossary. In: Bas C, Kuyper TW, Noordeloos ME and Vellinga EC (eds) Flora Agaricina Neerlandica. Vol. 1. AA Balkema, Rotterdam, pp. 54-64. 
Verbeken A, 1998a. Studies in tropical African Lactarius species. 5. A synopsis of the subgenus Lactifluus (Burl.) Hesler and A.H. Sm. Emend. Mycotaxon 66: 363-386.

Verbeken A, 1998b. Studies in tropical African Lactarius species. 6. A synopsis of the subgenus Lactariopsis (Henn.) R. Heim emend. Mycologia 66: 387-418.

Verbeken A, 2001a. Studies in tropical African Lactarius species. 10. Infrageneric classification. Mycotaxon 77: 435-444.

Verbeken A, 2001b. Worldwide systematics of Lactarius: a state of the art. Micologia $e$ Vegetazione Mediterranea 16: 71-88.

Verbeken A, Horak E, 1999a. Lactarius (Basidiomycota) in Papua New Guinea. 1. Species of tropical lowland habitats. Australian Systematic Botany 12: 767-779.

Verbeken A, Horak E, 1999b. Lactarius (Basidiomycota) in Papua New Guinea. 2. Species in tropical-montane rainforests. Australian Systematic Botany 13: 649-707.

Verbeken A, Horak E, 2002 ['2001']. Agaricales of Indonesia. 3. New recoreds of the genus Lactarius (Basidiomycota, Russulales) from Java. Sydowia 53: 261-289.

Wang XH, 2007. Type studies of Lactarius species published from China. Mycologia 99: 253-268.

Wang XH, Hashiya M, Verbeken A, 2006. Lactarius ochrogalactus, a new species of the genus Lactarius (Russulaceae, Russulales) with yellowish-brown latex. Mycoscience 47: 232234.

Wang XH, Liu P, Yu F, 2004. Color atlas of wild commercial mushrooms in Yunnan. Yunnan Science and Technology Press, Kunming

Wang XH, 2008. The genus Lactarius in southwestern China: taxonomy, ontogeny and floristic biogeography. Unpubl. Ph.D. dissertation, Kunming.

White TJ, Bruns T, Lee SS, Taylor J, 1990. Amplification and direct sequencing of fungal ribosomal RNA genes for phylogenetics. In: Innis MA, Gelfand DH, Sninsky JJ, White TJ 
(eds), PCR protocols: a guide to methods and applications. Academic Press, New York, pp. 315-322.

Wu Q, Mueller GM, 1997. Biogeographic relationships between the macrofungi of temperate eastern Asia and eastern North America. Canadian Journal of Botany 75: 2108-2116.

Wu QX, Mueller GM, Lutzoni FM, Huang YQ, Guo SY, 2000. Phylogenetic and biogeographic relationships of eastern Asian and eastern North American disjunct Suillus species (Fungi) as inferred from nuclear ribosomal RNA ITS sequences. Molecular Phylogenetics and Evolution 17: 37-47.

Zhang LF, Yang JB, Yang, ZL, 2004. Molecular phylogeny of eastern Asian species of Amanita (Agaricales, Basidiomycota): taxonomic and biogeographic implications. Fungal Diversity 17: 219-238. 


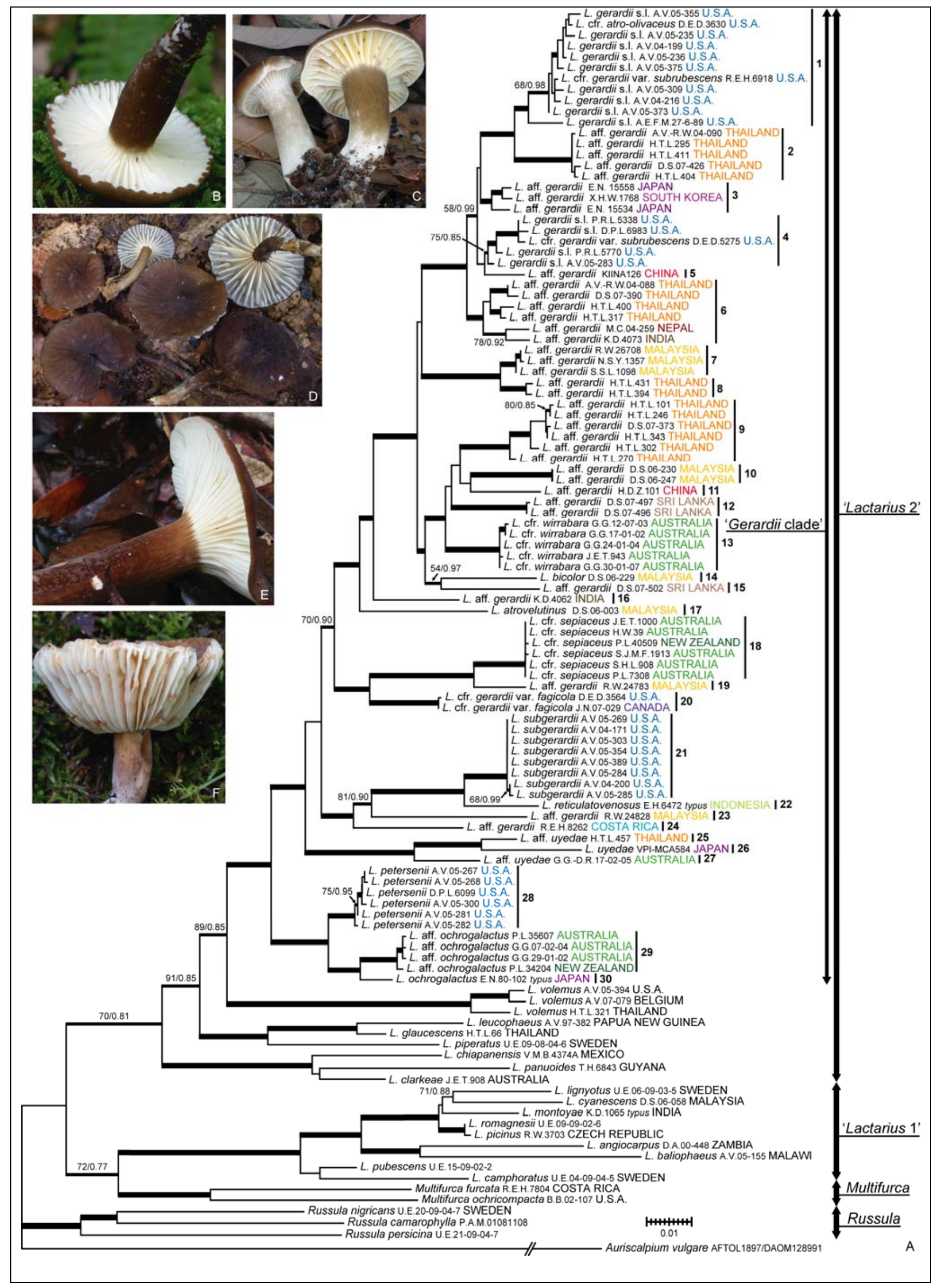


Fig 1 - (A) The best ML tree based on the combined analysis of ITS, LSU and rpb2 sequences, resulting from a 500 replicates Rapid Bootstrapping algorithm and a ML tree search in RAxML. Thickest branches are supported with min. $70 \%$ BS support and 0.95 posterior probability (PP). Branches supported by either the ML or the BI analysis are semithickened and support values are given. Numbered clades are discussed in the text. (B) Lactarius gerardii s.l. from the U.S.A., clade 1, A. Verbeken 05-309, (C) L. atrovelutinus from Malaysia, with pinkening latex, clade 17, D. Stubbe 06-003 (photograph: R. Walleyn), (D) L. bicolor from Malaysia with distinctly coloured lamella edges, clade $14, D$. Stubbe 06229, (E) L. aff. gerardii from Sri Lanka with dense lamellae, clade 15, D. Stubbe 07-502, (F) L. petersenii from the U.S.A. with brown latex, clade 28, A. Verbeken 05-268. 


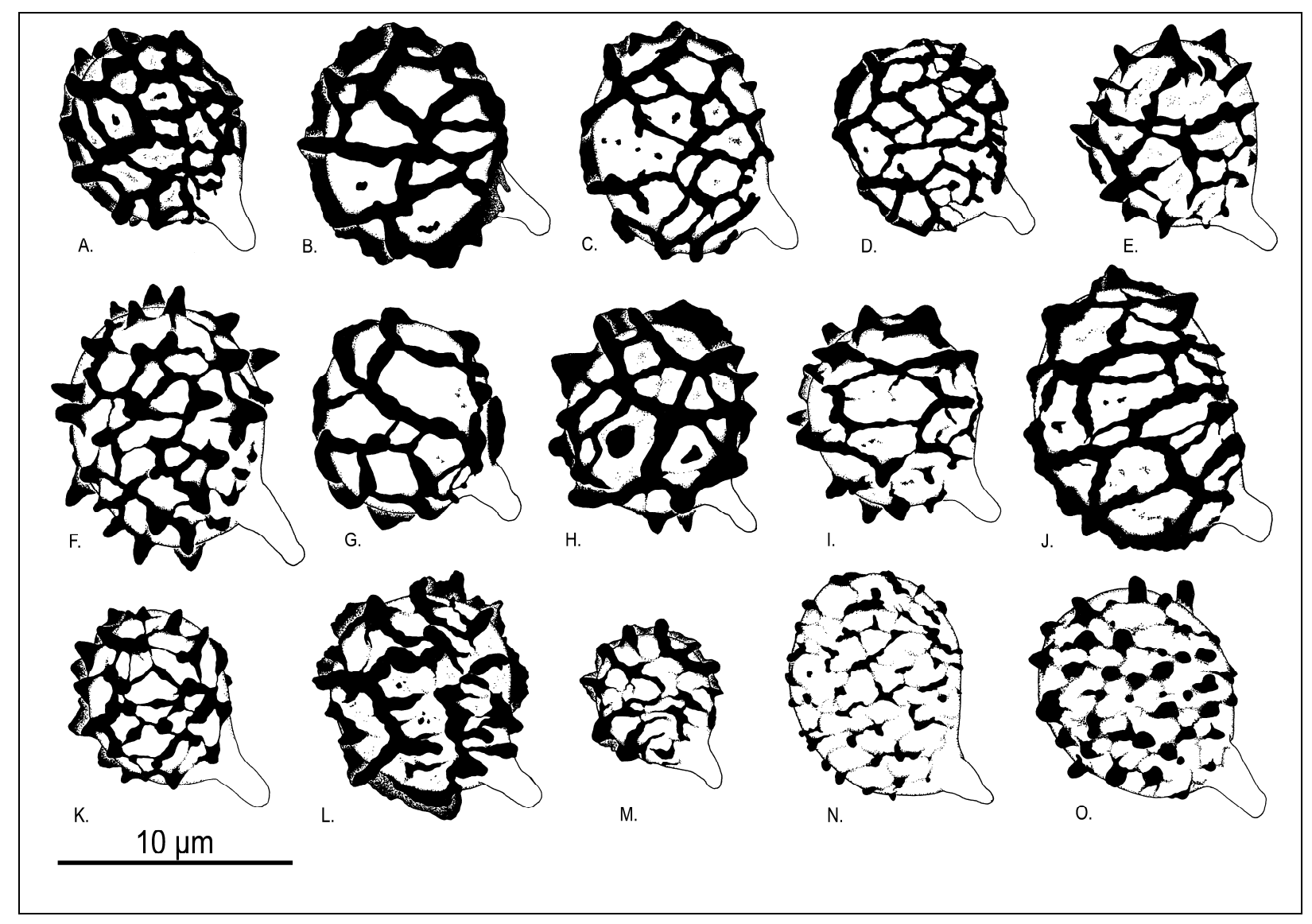

Fig 2 - Examples of the different spore morphologies: (A) Lactarius gerardii s.l., U.S.A., clade1, A. Verbeken 04-199, (B) L. aff. gerardii, Thailand, clade 2, D. Stubbe 07-426, (C) L. aff. gerardii, South Korea, clade 3, X.H. Wang 1768, (D) L. aff. gerardii, Thailand, clade 8, H.T. Le 394, (E) L. cfr. wirrabara, Australia, clade 13, J.E. Tonkin 943, (F) L. aff. gerardii, Sri Lanka, clade 12, D. Stubbe 07-496, (G) L. aff. gerardii, Malaysia, clade 10, D. Stubbe 06230, (H) L. aff. gerardii, Sri Lanka, clade 15, D. Stubbe 07-502, (I) L. cfr. sepiaceus, Australia, clade 18, S.J. McMullan-Fisher 1913, (J) L. cfr. gerardii var. fagicola, Canada, clade 20, J. Nuytinck 07-029, (K) L. subgerardii, U.S.A., clade 21, A. Verbeken 04-200, (L) L. reticulatovenosus, Indonesia, clade 22, typus, (M) L. aff. uyedae, Thailand, clade 25, H.T. Le 457, (N) L. petersenii, U.S.A., clade 28, A. Verbeken 05-300, (O) L. aff. ochrogalactus, Australia, clade 29, P. Leonard 35607. 


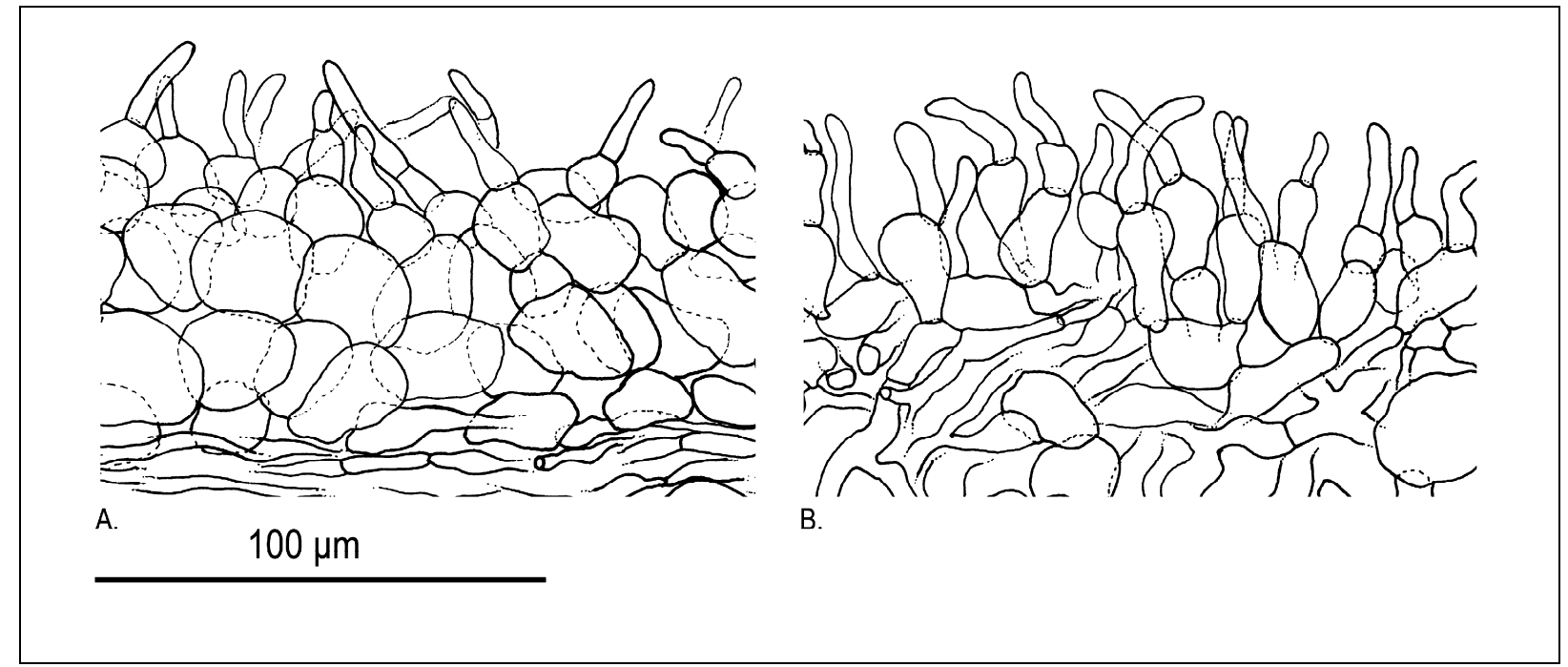

Fig 3 - Comparison of the typical pileipellis found in Lactarius subg. Gerardii and the one found in L. subg. Plinthogalus: (A) L. aff. gerardii, Thailand, H.T. Le 295, (B) L. picinus Fr., Czech Republic, R. Walleyn 3703. 
Table 1 - Specimens and GenBank accession numbers of DNA sequences used in the

molecular analyses. Accession numbers of newly produced sequences are indicated in bold.

\begin{tabular}{|c|c|c|c|c|c|}
\hline spe & Original identification & Voucher & Location & no. & no. \\
\hline
\end{tabular}

Lactarius

L. atrovelutinus

L. bicolor

L. chiapanensis

L. aff. gerardii

L. aff. gerardii

L. aff. gerardii

L. aff. gerardii

L. aff. gerardi

L. aff. gerardii

L. aff. gerardii

L. aff. gerardii

L. aff. gerardii

L. aff. gerardii

L. aff. gerardii

L. aff. gerardii

L. aff. gerardii

L. aff. gerardii

L. aff. gerardii

L. aff. gerardii

L. aff. gerardit

L. aff. gerardii

L. aff. gerardii

L. aff. gerardii

L. aff. gerardi

L. aff. gerardit

L. aff. gerardii

L. aff. gerardii

L. aff. gerardii

L. aff. gerardii

L. aff. gerardi

L. aff. gerardit

L. aff. gerardii

L. aff. gerardii

L. aff. gerardii

L. aff. gerardii

L. aff. gerardii

L. aff. gerardi

L. aff. gerardii

L. gerardii s.I.

L. gerardii s.I.

L. gerardii s.I.

L. gerardii s.I.

L. ochrogalactus

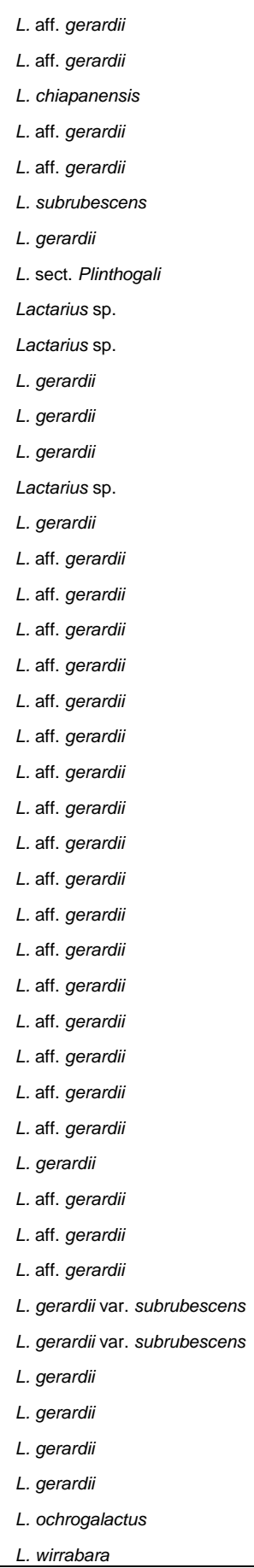

D.Stubbe 06-003 (GENT)

D.Stubbe 06-229 (GENT)

V.M.Bandala 4374A (GENT)

D.Stubbe 06-230 (GENT)

D.Stubbe 06-247 (GENT)

R.Watling $24828(\mathrm{E})$

R.Watling 24783 (E)

R.Watling 26708 (E)

S.N.Yahya, FRIM1357 (FRIM)

S.S.Lee, FRIM1098 (FRIM)

E.Nagasawa, TMI15558 (TMI)

E.Nagasawa, TMI15534 (TMI)

X.H.Wang 1768 (HKAS)

KIINA 126 (GENT)

H.D.Zheng 101 (HKAS)

H.T.Le 295 (GENT)

D.Stubbe/R.Walleyn 07-426 (GENT)

Selangor, Malaysia
Negeri Sembilan, Malaysia
Chiapas, Mexico

Chiapas, Mexico

Negeri Sembilan, Malaysia

Negeri Sembilan, Malaysia

Negeri Sembilan, Malaysia

Negeri Sembilan, Malaysia

Negeri Sembilan, Malaysia

Selangor, Malaysia

Selangor, Malaysia

Aomori, Japan

Tottori, Japan

South Korea

Hunan, China

Yunnan, China

Chiang Mai, Thailand

Chiang Mai, Thailand

A.Verbeken/R.Walleyn 04-090 (GENT) Chiang Mai, Thailand

H.T.Le 404 (GENT)

Chiang Mai, Thailand

Chiang Mai, Thailand

A.Verbeken/R.Walleyn 04-088 (GENT) Chiang Mai, Thailand

D.Stubbe 07-390 (GENT)

H.T.Le 317 (GENT)

H.T.Le 400 (GENT)

H.T.Le 394 (GENT)

H.T.Le 431 (GENT)

H.T.Le 270 (GENT)

H.T.Le 343 (GENT)

H.T.Le 246 (GENT)

D.Stubbe/R.Walleyn 07-373 (GENT)

H.T.Le 101 (GENT)

H.T.Le 302 (GENT)

M.Christensen 04-259 (GENT)

D.Stubbe 07-496 (GENT)

D.Stubbe 07-497 (GENT)

D.Stubbe 07-502 (GENT)

K.Das 4073 (BSD)

K.Das 4062 (BSD)

A. Verbeken 05-355 (GENT)

A.E.Franco-Molano 27-6-89 (NY)

A. Verbeken 05-283 (GENT)

P.R.Leacock 5338 (F)

E. Nagasawa 80-102 = typus $(\mathrm{TMI})$

G.Gates 29-01-02
GU258233

\begin{tabular}{|c|c|c|}
\hline GU258231 & GU265588 & GU258325 \\
\hline GU258221 & GU265577 & GU258313 \\
\hline GU258297 & GU265580 & GU258316 \\
\hline GU258222 & GU265578 & GU258314 \\
\hline GU258223 & GU265579 & GU258315 \\
\hline \multirow{2}{*}{$\begin{array}{l}\text { GU258275 } \\
-\end{array}$} & GU265636 & GU258374 \\
\hline & GU265637 & GU258375 \\
\hline - & GU265590 & GU258327 \\
\hline GU258233 & GU265591 & GU258328 \\
\hline GU258232 & GU265589 & GU258326 \\
\hline GU258230 & GU265587 & GU258324 \\
\hline GU258229 & GU265586 & GU258323 \\
\hline GU258225 & GU265583 & GU258319 \\
\hline \multirow{2}{*}{$\begin{array}{l}\text { GU258227 } \\
\text { GU258226 }\end{array}$} & \multirow{2}{*}{$\begin{array}{l}\text { GU265584 } \\
-\end{array}$} & GU258321 \\
\hline & & GU258320 \\
\hline EF560687 & GU265600 & GU258337 \\
\hline GU258241 & GU265602 & GU258339 \\
\hline GU258244 & GU265605 & GU258342 \\
\hline GU258245 & GU265606 & GU258343 \\
\hline GU258250 & GU265611 & GU258348 \\
\hline GU258239 & GU265597 & GU258334 \\
\hline GU258252 & GU265613 & GU258350 \\
\hline GU258243 & GU265604 & GU258341 \\
\hline GU258246 & GU265607 & GU258344 \\
\hline GU258249 & GU265610 & GU258347 \\
\hline GU258251 & GU265612 & GU258349 \\
\hline EF560685 & GU265598 & GU258335 \\
\hline GU258240 & GU265599 & GU258336 \\
\hline EF560686 & GU265601 & GU258338 \\
\hline GU258242 & GU265603 & GU258340 \\
\hline GU258247 & GU265608 & GU258345 \\
\hline GU258248 & GU265609 & GU258346 \\
\hline GU258234 & GU265592 & GU258329 \\
\hline GU258236 & GU265594 & GU258331 \\
\hline GU258237 & GU265595 & GU258332 \\
\hline GU258238 & GU265596 & GU258333 \\
\hline GU258274 & - & GU258373(incompl.) \\
\hline GU258228 & GU265585 & GU258322 \\
\hline GU258253 & GU265615 & GU258352 \\
\hline- & - & GU258377 \\
\hline GU258259 & GU265621 & GU258358 \\
\hline GU258261 & GU265623 & GU258360 \\
\hline GU258280 & - & GU258381 \\
\hline GU258304 & GU265664 & GU258404 \\
\hline
\end{tabular}




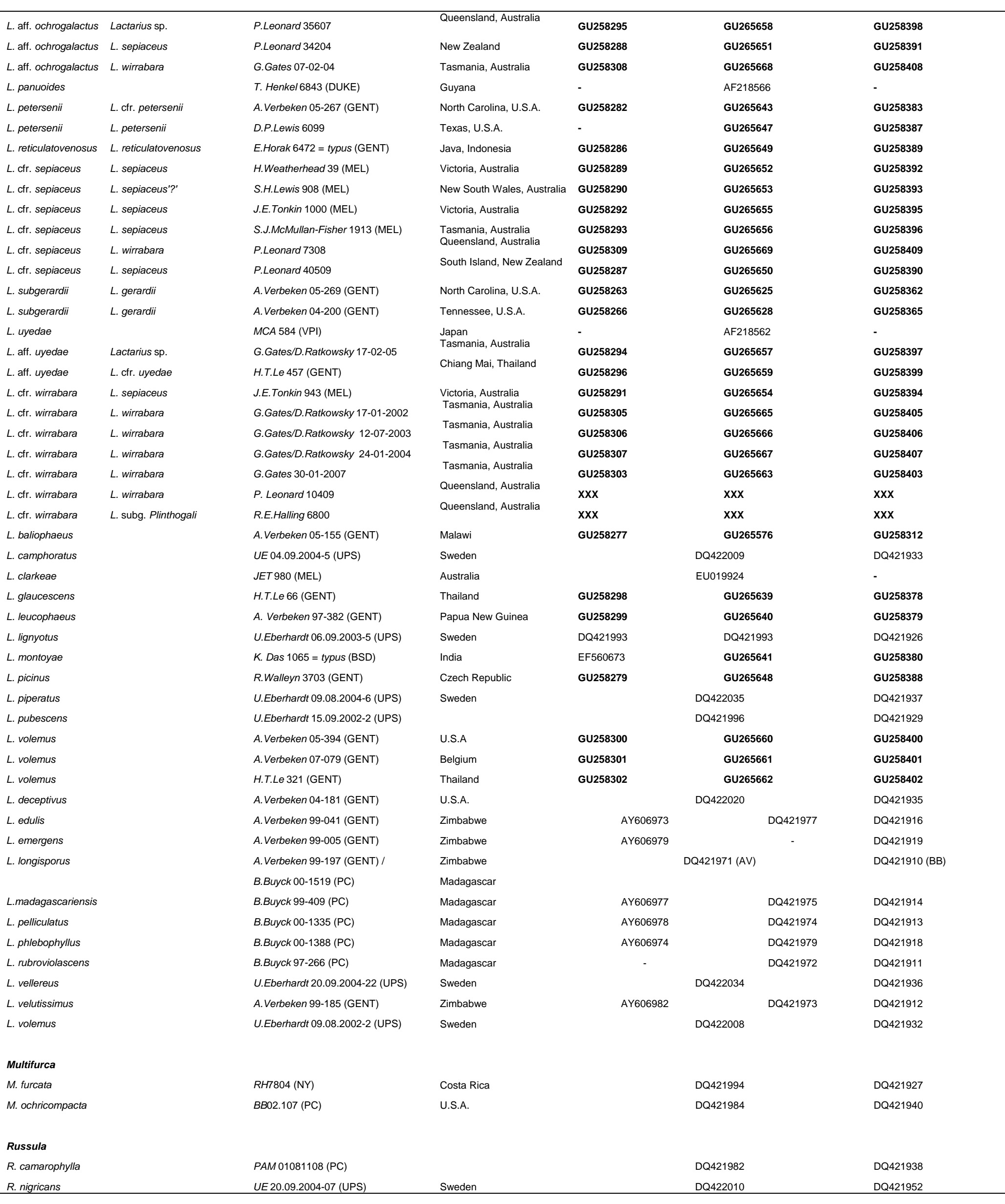


